\title{
EFFECTS OF FEAR-CONDITIONING AND ELECTRIC SHOCK ON INORGANIC-NUTRIENT SELECTION IN THE ALBINO RAT ${ }^{1}$
}

\author{
TSUYOSHI SHIGEHISA
}

Department of Psychology, Waseda University

A previous investigation has shown that in the self-selections of $\mathrm{NaCl}, \mathrm{NaH}_{2} \mathrm{PO}_{4}, \mathrm{~K}_{2} \mathrm{HPO}_{4}$, calcium-lactate, $\mathrm{MgSO}_{4}$ and ferric-citrate for more than 40 days, each normal albino rat performed a constant selection in spite of large individual differences.

Constant patterns were observed among several inorganic salt selections throughout the experiment.

Selection order of each salt except an unexpected increase in $\mathrm{NaCl}$ selection was as follows ; calcium-lactate, $\mathrm{K}_{2} \mathrm{HPO}_{4}, \mathrm{NaH}_{2} \mathrm{PO}_{4}, \mathrm{MgSO}_{4}$, ferric-citrate.

As the result, ratio of selection (per cent) of each inorganic salt fairly corresponded to that of the composition of McCollum's salt mixture (SHIGEHISA; 1963).

According to the data, if the dietary supply of those salts are adequate, animals may perform continually constant selections of those salts.

In the present study, effects of fear-conditioning and electric-shock stimulation in an unavoidable situation on the self-selections of $\mathrm{NaCl}$, $\mathrm{NaH}_{2} \mathrm{PO}_{4}, \mathrm{~K}_{2} \mathrm{HPO}_{4}$, calcium-lactate, $\mathrm{MgSO}_{4}$ and ferric-citrate were discussed on the basis of these results in the case of the albino rat.

1) A part of the present study was reported at the 26 th Annual Meeting of the Japanese Psychological Association (1962).

2) All the salts used were the extra pure reagent chemicals. 


\section{Method}

Subject and Apparatus: Subjects and apparatus used in the present study were same as previous report (SHIGEHISA).

Nutrient: Inorganic salt water solutions subjected to the selection were as follows ; $3 \% \mathrm{NaCl}, 4 \% \mathrm{NaH}_{2} \mathrm{PO}_{4}, 1 \% \mathrm{~K}_{2} \mathrm{HPO}_{4}, 2 \%$ calciumlactate, $1 \% \mathrm{MgSO}_{4}$ and $2 \%$ ferric-citrate ${ }^{2}$. They were prepared every 5 days.

Experimental procedure: Each rat was maintained in an individual metabolism cage in which $30 \mathrm{ml}$. inverted drinking tubes were arranged with equal distance.

Each inorganic salt solution was put on a different position in a cage at random every day using individual drinking tubes, and the volume of selections was measured every 24 hours.

The volume of selections was measured on $1 \mathrm{ml}$. by the graduation of tubes and solutions were renewed everyday.

Besides salts, starch (P. H. Jap. VI), olive oil, vitamin free casein, cod liver oil and dry yeast and distilled water were fed ad libitum.

Besides, fear-conditioning and electric-shock stimulation, measurement of jumping latencies, experimental period and grouping were the same technique as used in a previous study (SHIGEHISA).

\section{Results and Discussion}

Selections were averaged every 5 days and converted to milligram selections per day and shown in mean of each group.

Animals in 4 groups performed constant selections throughout the experiment in each salt selection with larger individual differences except 2 salts in experimental groups.

As reported in a previous study, animals in both experimental groups exhibited marked behavior changes during and after the stimulation periods (period 3 and 4) (SHIGEHISA).

Selections of calcium-lactate and $\mathrm{K}_{2} \mathrm{HPO}_{4}$ fluctuated markedly in the self-selection coincidentally with the behavior changes (Fig. 1,2). 


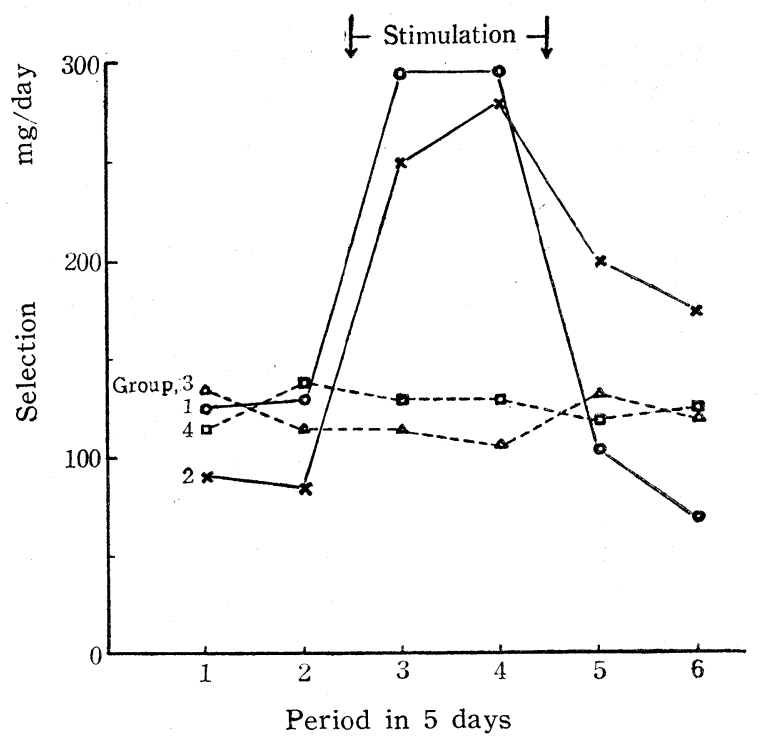

Fig. 1 Calcium-lactate selection

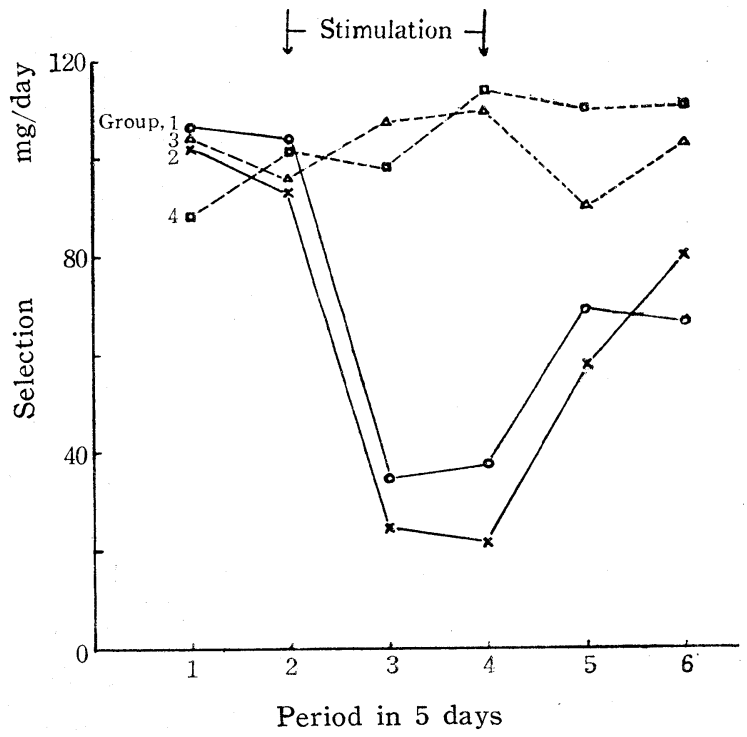

Fig. $2 \mathrm{~K}_{2} \mathrm{HPO}_{4}$ selection 
Jumping on a barrier and then jumping into the next small room occurred within 60 sec. during the stimulation period (period 3) for the first time and then the period 4,5 and 6 .

Calcium-lactate selection increased and $\mathrm{K}_{2} \mathrm{HPO}_{4}$ selection decreased in both experimental groups during and after the stimulation periods according to fear-conditioning and electric shock stimulation.

Calcium-lactate selection recovered rapidly in both groups and then decreased to less than the value before stimulation during the period 5 and 6 without stimulations in Group 1 (Fig. 1).

Potassium hydrogen phosphate selection in both groups tended to recover gradually during the period 5 and 6 (Fig. 2).

Selections of $\mathrm{NaH}_{2} \mathrm{PO}_{4}, \mathrm{MgSO}_{4}$ and ferric-citrate were maintained constant during any of the period in all groups (but a slight tendency toward increase in $\mathrm{MgSO}_{4}$ selection was observed) (Fig. 3, 4, 5,6).

Selections of calcium-lactate and $\mathrm{K}_{2} \mathrm{HPO}_{4}$ remained constant throughout the experiment in both control groups (Fig. 1,2).

According to the result, it is suggested that the increase of calciumlactate selection was resulted from the incremental selection of calcium,

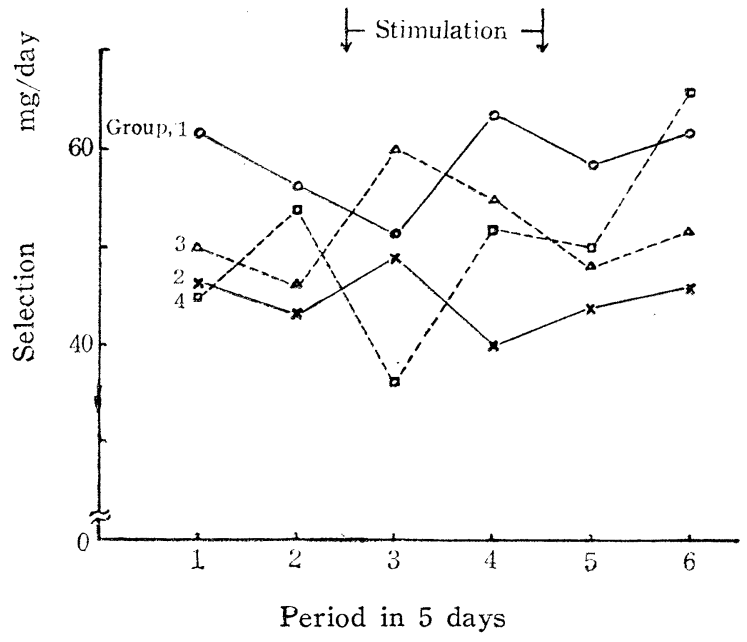

Fig. $3 \mathrm{NaCl}$ selection because only source of calcium among inorganic salts subjected to the selection was calcium-lactate, and $\mathrm{CaCl}_{2}$ was also used in this experiment and then the same result was obtained.

It is also suggested that the decrease of $\mathrm{K}_{2} \mathrm{HPO}_{4}$ selection was resulted from the decremental selection 
Shigehisa : Fear Conditioning in Rat

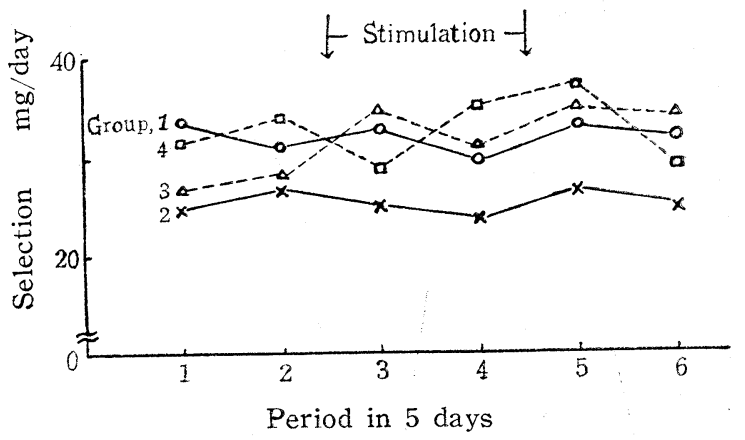

Fig. $4 \mathrm{NaH}_{2} \mathrm{PO}_{4}$ selection

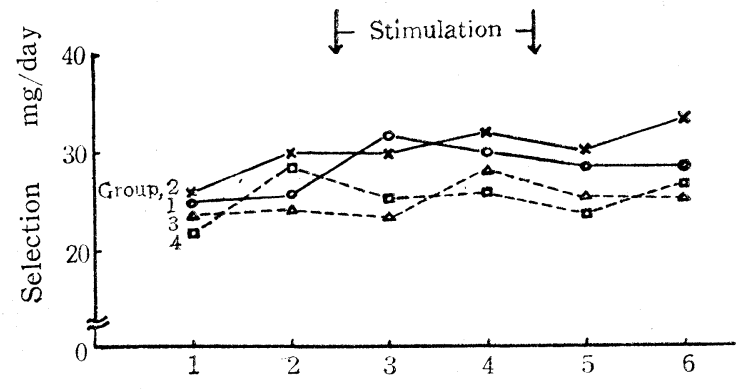

Period in 5 days

Fig. $5 \mathrm{MgSO}_{4}$ selection

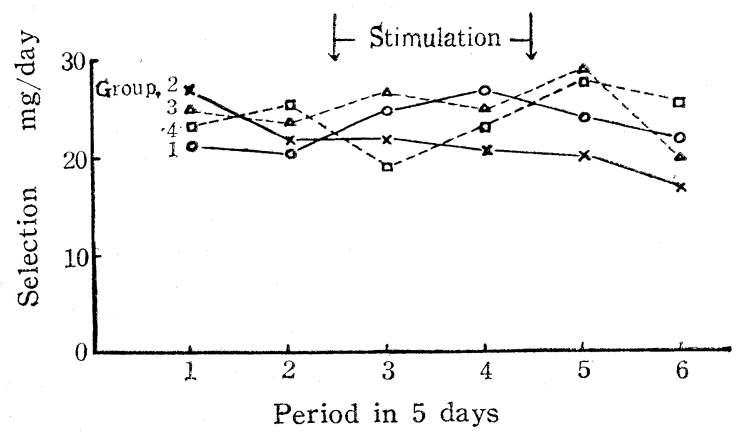

Fig. 6 Ferric-citrate selection 


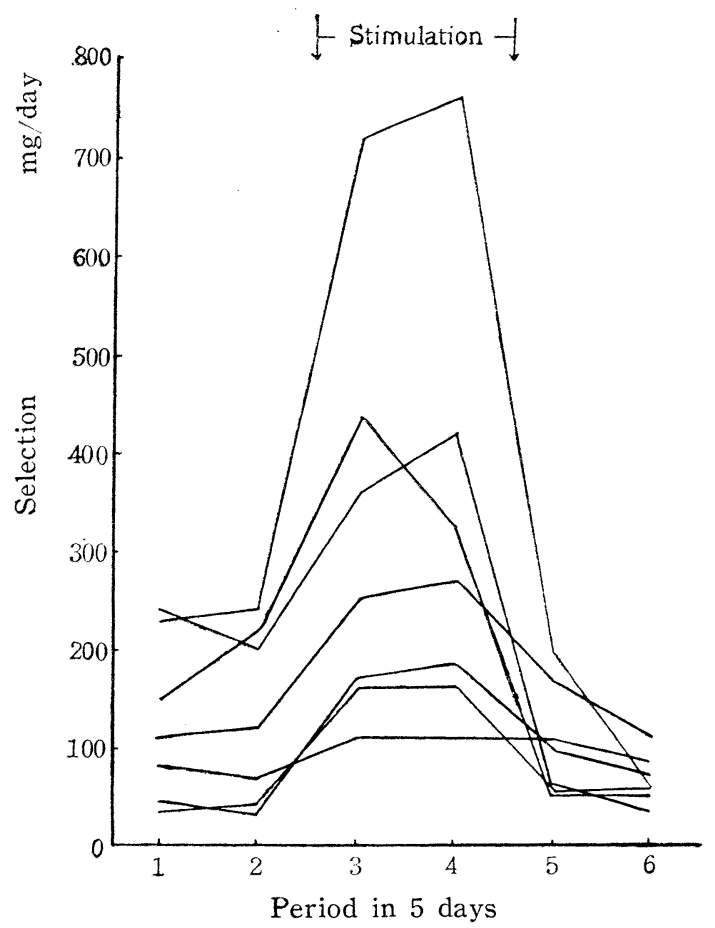

Fig. 7 Calcium-lactate selections of Group 1 animals of potassium rather than phosphate, because only source of potassium was $\mathrm{K}_{2}$ $\mathrm{HPO}_{4}$, and $\mathrm{K}_{2} \mathrm{HPO}_{4}$ selection alone decreased whereas $\mathrm{Na}$. $\mathrm{H}_{2} \mathrm{PO}_{4}$ selection did not decrease, though $\mathrm{NaH}_{2} \mathrm{PO}_{4}$ was also subjected to the selection at the same time under the same condition as a source of phosphate other than $\mathrm{K}_{2} \mathrm{HPO}_{4}$.

Calcium-lactate selection increased and $\mathrm{K}_{2} \mathrm{HPO}_{4}$ selection decreased in all animals in experimental groups as shown in Fig. 7,8,9 and 10.

Individual differences among calcium-lactate selections increased during the period 3 and $4(\mathrm{SD}=201,213)$ and decreased during the period 5 and $6(\mathrm{SD}=31,26)$ as compared with the period 1 and 2 $(\mathrm{SD}=75,83)$ in Group 1. They increased during the period $3,4,5$ and $6(\mathrm{SD}=174,145,110,92)$ as compared with the period 1 and 2 (SD $=43,37$ ) in Group 2 .

Among $\mathrm{K}_{2} \mathrm{HPO}_{4}$ selections they increased during the period $3,4,5$ and $6(\mathrm{SD}=25,33,52,51)$ as compared with the period 1 and 2 (SD $=55,46)$ in Group 1 . They increased during the period 3 and 4 (SD $=29,24)$, and decreased during the period 5 and $6(\mathrm{SD}=21,28)$ as compared with the period 1 and $2(\mathrm{SD}=58,57)$ in Group 2 .

Especially two types were noted among animals in both experi- 
Shigenisa : Fear Conditioning in Rat

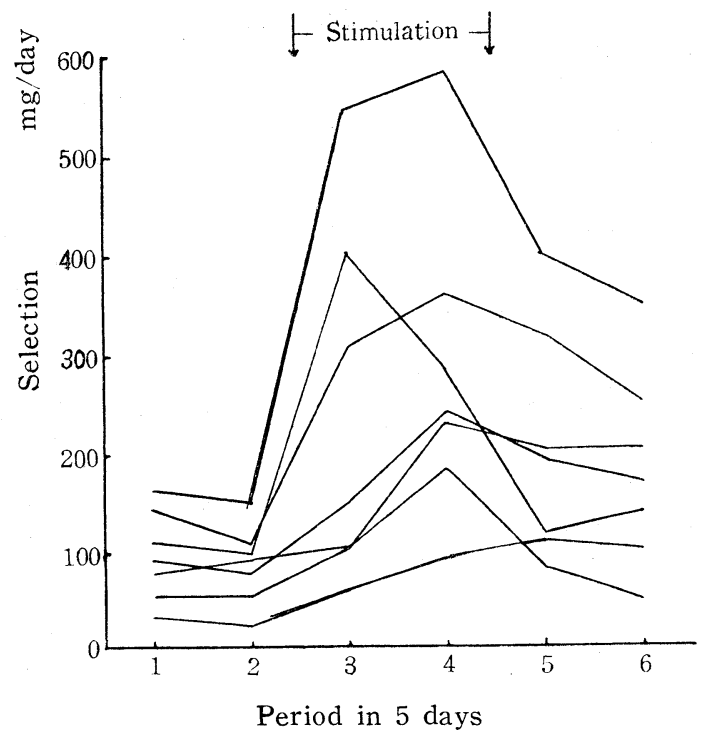

Fig. 8 Calcium-lactate selections of Group 2 animals

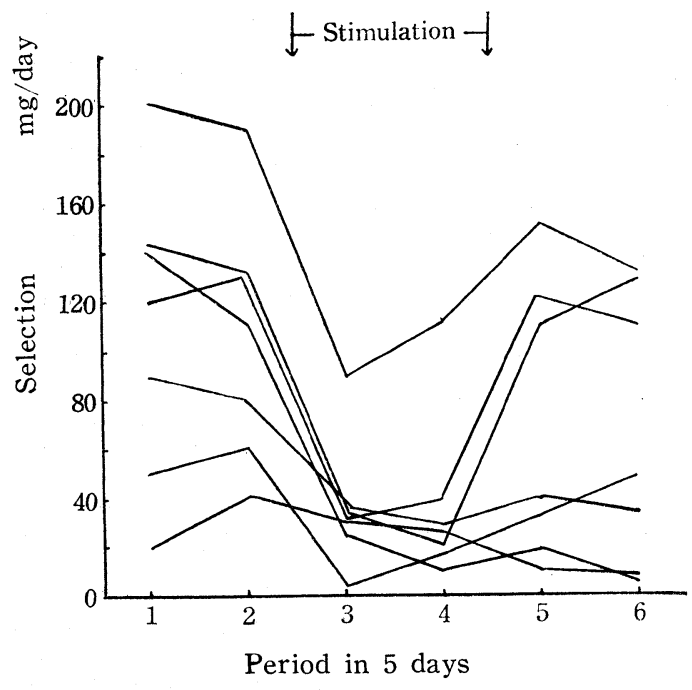

Fig. $9 \mathrm{~K}_{2} \mathrm{HPO}_{4}$ selections of Group 1 animals 


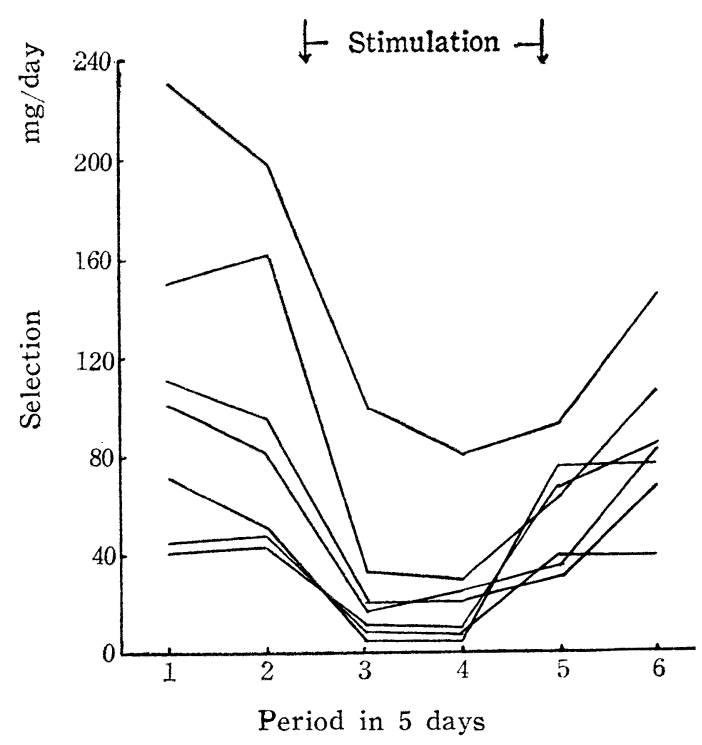

Fig. $10 \mathrm{~K}_{2} \mathrm{HPO}_{4}$ selections of Group 2 animals

mental groups in the mode of increase in calcium-lactate selection. In the first type, the selections were small before stimulation. They increased markedly during stimulation and then recovered gradually after the stimulation. In the second type, the volume of selections was fairly large before stimulation. They increased slightly during stimulation and recovered rapidly after the stimulation.

The increase in selection during the period 4 was generally larger than that during the period 3 in the second type as compared with the first one. (Fig. 7, 8).

In the decremental selection of $\mathrm{K}_{2} \mathrm{HPO}_{4}$, the same tendency was noted. That is, in the first type, the volume of selections was large before stimulation and decreased rapidly during stimulation. The recovery was large and rapid, and then reached to the value before stimulation in Group 1, whereas it was small and gradual in Group 2. In the second type, the volume of selections was small before stimulation and decreased gradually during stimulation. It recovered rapidly and reached to the value before stimulation or near that value in Group 
2, whereas recovered slowly in Group 1 (Fig. 9, 10).

The average percentage of increase in calcium-lactate selection during stimulation periods reached at 261 and 271 per cent $(\mathrm{SD}=95,110)$ of selection during the period 2 in Group 1, and 312 and 350 per cent $(\mathrm{SD}=87,88)$ in Group 2. The selection recovered to 125 per cent $(\mathrm{SD}=52)$ in Group 1 , and 250 and 219 per cent $(\mathrm{SD}=128,139)$ in Group 2 during the period 5 and 6 without stimulations. And then decreased to 93 per cent $(\mathrm{SD}=51)$ in Group 1 during the period 6 .

The average percentage of decrease in $\mathrm{K}_{2} \mathrm{HPO}_{4}$ selection during stimulation periods reached at 34 and 35 per cent $(\mathrm{SD}=21,19)$ in Group 1, and 27 and 23 per cent $(\mathrm{SD}=11,12)$ in Group 2. The selection recovered to 57 and 58 per cent $(\mathrm{SD}=28,29)$ in Group 1 , and 62 and 85 per cent $(\mathrm{SD}=46,50)$ in Group 2 during the period 5 and 6 without stimulations.

Calcium-lactate selection increased significantly (t-test) at the .025 level in Group 1 and the .01 level in Group 2 during stimulation periods and perfectly recovered in all animals during the period 5 , and then decreased significantly at the .025 level in Group 1 and the .01 level in Group 2 during the period 6 without stimulations.

In Group 1, the decrease of $\mathrm{K}_{2} \mathrm{HPO}_{4}$ selection was significant at the .005 level during stimulation periods, and at the .01 level during the period 5 , and the .025 level during the period 6 in which tendencies of recovery were shown in few animals. In Group 2, it decreased at the .01 level during stimulation periods, and at the . 025 level during the period 5 , and the .05 level during the period 6 .

Comparing fluctuations in the selections of calcium-lactate and $\mathrm{K}_{2} \mathrm{HPO}_{4}$ among animals in experimental groups during and after the stimulation period, percentage of selection in maximally fluctuated period to each control (period 2) selection (refer to a previous report (SHIGEHISA)) shows that the decrease in $\mathrm{K}_{2} \mathrm{HPO}_{4}$ selection was generally large in animals in which the increase in calcium-lactate selection was large as shown in Table 1 and 2 .

Inverse correlational tendencies (Group 1, $\mathrm{r}=-.666$; Group 2, 
Table 1 Fluctuations of calcium-lactate and $\mathrm{K}_{2} \mathrm{HPO}_{4}$ selections in Group 1 animals (Percentage of maximum fluctuation in Group 1 animals)

\begin{tabular}{|ccc|c|}
\hline Period & $\begin{array}{c}\text { Period } 2 \\
\text { Subject }\end{array}$ & \multicolumn{2}{c|}{ Maximally fluctuated period } \\
\hline 1 & 100 & Calcium-lactate & $\mathrm{K}_{2} \mathrm{HPO}_{4}$ \\
\hline 2 & 100 & 225 & 5 \\
\hline 3 & 100 & 389 & 5 \\
\hline 4 & 100 & 447 & 20 \\
\hline 5 & 100 & 164 & 38 \\
\hline 6 & 100 & 317 & 47 \\
\hline 7 & 100 & 210 & 23 \\
\hline
\end{tabular}

Table 2 Fluctuations of calcium-lactate and $\mathrm{K}_{2} \mathrm{HPO}_{4}$ selections in Group 2 animals. (Percentage of maximum fluctuation in Group 2 animals)

\begin{tabular}{|c|c|c|c|}
\hline Period & $\begin{array}{c}\text { Period } 2 \\
\text { (control) }\end{array}$ & \multicolumn{2}{|c|}{ Maximally fluctuated period } \\
\hline Subject & 100 & 158 & $\mathrm{~K}_{2} \mathrm{HPO}_{4}$ \\
\hline 1 & 100 & 310 & 21 \\
\hline 2 & 100 & 285 & 19 \\
\hline 3 & 100 & 387 & 12 \\
\hline 4 & 100 & 123 & 6 \\
\hline 5 & 100 & 405 & 43 \\
\hline 6 & 100 & 202 & 10 \\
\hline 7 & & & 19 \\
\hline
\end{tabular}

$r=-.925)$ were observed between them.

The present result in both experimental groups was not based on each independent fluctuation of calcium-lactate and $\mathrm{K}_{2} \mathrm{HPO}_{4}$ selections, is readily conceivable according to the following points ;

1) Fluctuations in the both salts selections started at the same time.

2) And then mode of both fluctuations was inversely proportional. 
3) Considering the fact neuro-physiologically, effects of calcium and potassium on neural excitement are antagonistic each other.

It is suggested that excess in calcium resulted from the increased selection of calcium-lactate resulted anesthetizing effect on animals, and the effect was accelerated by the decreased selection of potassium.

According to that result behavior depressive states were intensified and then depressive tendencies were dominant after the stimulation periods in the present study.

It is difficult to conclude on what kind of mechanisms such an excessive ingestion of calcium and a limited ingestion of potassium are based.

However, sedative effect of calcium and exciting effect of potassium suggest that fluctuations in both salts selections coincide with fluctuations in physiological needs.

It was reported that according to dietary deficiencies of phosphorus, ferrous and sodium (Hellwald, 1931 ; Katz, 1937 ; Falk, 1961), adrenalectomy (Richter, 1936), and running in the treadmill (Griffiths, 1956) regular selections of phosphorus, calcium, ferrous, sodium and potassium in animals were fluctuated.

According to these results, it is suggested that fluctuations in calcium and potassium selections in the present experiment were resulted from metabolic deficiency or excess of each metabolite.

Some kinds of relation are conceivable between abnormal behaviors of animals elicited by the fear-conditioning or electric shock stimulation and fluctuations in metabolic conditions resulted in the fluctuation of calcium and potassium ingestions.

Fluctuations in the salt selections in experimental groups manifested under the condition such as confinement of animals into the room which was very different from living cages in which presentations of auditory and painful stimuli or painful stimulus alone were conducted during extremely limited hours per day continuously for long term.

However, direct relations between fluctuations in the salt selection and factors other than painful stimulus are uncertain. For the results 
in both groups were very similar with each other and the procedure common to both groups was the presentation of shock.

The occurrence of primary emotional response by the shock stimulation was suggested by the marked behavioral changes which were very similar in both experimental groups.

According to the result in both experimental groups, general tendencies of behavior depression and increase in startling manifested continually in living cages may be primary responses elicited by the electric shock per se as a painful stimulus.

Therefore, it is suggested that the main factor of the present result is an emotional state based on the electric shock stimulation.

\section{SUMMARY}

Effects of fear-conditioning and electric-shock on the self-selections of $3 \% \mathrm{NaCl}, 4 \% \quad \mathrm{NaH}_{2} \mathrm{PO}_{4}, 1 \% \mathrm{~K}_{2} \mathrm{HPO}_{4}, 2 \%$ calcium-lactate, $1 \%$ $\mathrm{MgSO}_{4}$ and $2 \%$ ferric-citrate water solutions were discussed.

Wistar strain albino rats were subjected to the selection of each inorganic salt which was presented by the individual drinking tube and the selections were measured every 24 hours.

Experiment was consisted of 30 days in 6 periods of 5 days.

In Group 1, buzzer (A. C. 4 V., for $5 \mathrm{sec}$.) and electric shock (A. C. $.5 \mathrm{~mA}$., $100 \mathrm{~V}$., for $.2 \mathrm{sec}$.) were presented with $5 \mathrm{sec}$. intervals for 10 times within $30 \mathrm{~min}$. per day for 10 days during the period 3 and 4.

In Group 2, electric shock alone was presented under the same condition as Group 1.

Group 3 animals were put in a grid box without any stimulations under the same condition as Group 1.

Group 4 animals were subjected to the selection without any of these treatments.

Body weight increase in Group 1 and 2 was retarded during the period 3 and 4, and then increased markedly during the period 5 . Jumping on a barrier and then into the next small room occurred 
within $60 \mathrm{sec}$. for the first time during the period 3 and then 4,5 and 6 in Group 1 and 2. Both jumping latencies decreased rapidly and then recovered gradually.

In Group 1 and 2, marked behavior changes were observed during and after the period 3 and 4 which were parallelly proceeded with fluctuations in calcium-lactate and $\mathrm{K}_{2} \mathrm{HPO}_{4}$ selections.

In both groups, calcium-lactate selection increased rapidly during the period 3 and 4 and then recovered rapidly during the period 5 and 6. It reached to less than the value during the period 1 and 2 in Group 1.

Potassium hydrogen phosphate selection decreased rapidly during the period 3 and 4 in both groups and then tended to recover gradually during the period 5 and 6 .

Calcium-lactate selection increased and $\mathrm{K}_{2} \mathrm{HPO}_{4}$ selection decreased in all animals.

Calcium-lactate and $\mathrm{K}_{2} \mathrm{HPO}_{4}$ selections in Group 3 and 4 were almost constant throughout the experiment, and no significant fluctuations were observed.

Sodium chloride, $\mathrm{NaH}_{2} \mathrm{PO}_{4}, \mathrm{MgSO}_{4}$ and ferric-citrate selections were very similar among 4 groups during any of the period.

It is suggested that calcium-lactate selection was increased because of calcium. For only source of calcium was calcium-lactate, and the same result was obtained in the case of $\mathrm{CaCl}_{2}$ which was used instead of calcium-lactate.

It is also suggested that $\mathrm{K}_{2} \mathrm{HPO}_{4}$ selection was decreased because of potassium. For only $\mathrm{K}_{2} \mathrm{HPO}_{4}$ selection was decreased in spite of simultaneous presentation of $\mathrm{NaH}_{2} \mathrm{PO}_{4}$ and $\mathrm{K}_{2} \mathrm{HPO}_{4}$ as sources of phosphate.

Two types were noted among animals in both groups in the mode of fluctuation in calcium-lactate and $\mathrm{K}_{2} \mathrm{HPO}_{4}$ selections.

The average percentage of increase in calcium-lactate selection during the period 3 and 4 reached at 261 and 271 per cent of selection of the period 2 in Group 1, and 312 and 350 per cent in Group 2. And 
recovered to 125 per cent in Group 1, and 250 and 219 per cent in Group 2 during the period 5 and 6 , and then decreased during the period 6 to 93 per cent in Group 1.

The average percentage of decrease in $\mathrm{K}_{2} \mathrm{HPO}_{4}$ selection during the period 3 and 4 reached at 34 and 35 per cent in Group 1, and 27 and 23 per cent in Group 2, and recovered to 57 and 58 per cent in Group 1, and 62 and 85 per cent in Group 2 during the period 5 and 6.

Fluctuations in calcium-lactate and $\mathrm{K}_{2} \mathrm{HPO}_{4}$ selections were very similar in Group 1 and 2 respectively.

Inverse correlational tendency was noted between fluctuations of calcium-lactate and $\mathrm{K}_{2} \mathrm{HPO}_{4}$ selections.

Fluctuations in calcium-lactate and $\mathrm{K}_{2} \mathrm{HPO}_{4}$ selections may be related directly to the emotional state based on electric shock stimulation.

(Manuscript received October 4, 1962)

\section{ReFERENCES}

1. FALK J.L. ; The behavioral regulation of water electrolyte balance. Nebraska symposium on motivation, 1961, 1-33.

2. Griffiths W. J. Jr. ; Diet selections of rats subjected to stress. Ann. New York Acad. Sci., 1957, 67, 3-9.

3. Hellwald H., Untersuchungen über Triebstärken bei Tieren. Z. Psych., 1931, 123.

4. KATz D. ; Animals and men-Studies in comparative psychology. London; Longmans, Green and Co. Ltd., 1937.

5. Richter C. P. ; Increased salt appetite in adrenalectomized rats., Amer. J. Physiol. 1936, 115, 155-161.

6. Shigenisa T.; Studies on the diet selection in the albino rat. II. Selfselections of inorganic salts in the normal albino rats. J. Jap. Soc. Food Nutr. 1963, 15, 377-379. (In Japanese).

7. Shigenisa T.; Effects of fear-conditioning and electric shock on organic nutrient selection in the albino rat. Jap. Psychol. Research. (In press). 